\title{
A novel method to enhance ISSP compliant: An approach drawing upon the concept of empowerment in ERM system workflow
}

\author{
Soohyun Jeon \\ Korea University Business School \\ seanmetro@korea.ac.kr
}

\author{
Anat Hovav \\ Korea University Business School \\ anazth@korea.ac.kr
}

\begin{abstract}
Nowadays, enterprises employ information security system to protect organizational assets, then enforce employee to follow system workflow (i.e., information security policies). Although companies control employee by predefined workflow, employees tend to circumvent the workflow when the workflow is impeded and being inflexibility. Thus, the goal of this study is to delineate the new concept of system workflow, which is the method of increasing system workflow flexibility. We propose the notion of empowered system workflow through in the specific context of the enterprise digital rights management system (ERM). The ERM as an example of an information security system plays a role in persistently protecting information assets. This study examined the differences between the proposed notion of ERM system and the conventional ERM system through three aspects (psychological ownership, perceived benefit, and awareness of audit). The results of this study are expected to shed light on new approach to compliance behavior.
\end{abstract}

\section{Introduction}

Organizations establish and implement access control to protect organizational information assets. In addition, the organization strives to develop and maintain compliance with information security policy (ISSP) to properly employ the information security system. ISSP plays a role in inducing sanction-based motivation that enforces employee to comply with ISSP [1]. However, despite the efforts relating to sanctions, organizations still struggle with employee's noncompliant or negligent behavior.

Employees are not likely to follow ISSP when they perform a task urgently and when the ISSPs interfere with their task-performance [2]. A 2016 survey reported that 49 percent of the 2,000 desk-based workers surveyed in the UK and US had shared login ID and password with others (i.e., unauthorized co- workers and subordinates) to complete a task. ${ }^{1}$ This report implies that users often circumvent ISSP intentionally or accidentally. Sanction-based ISSP results in employee's violation because of misfit between ISSP and workflows [3]. That is, it is likely that when an unauthorized employee encounters exceptional cases (e.g., email to a third party), they are likely to complete the task by borrowed ID and password [4, 5]. Therefore, the stream of previous studies $[3,6,7]$ is consistent in that in the process of complying with ISSP can be considered concerning flexibility and not only in respect to enforcement.

ISSP compliance paradigm does not recognize the concept of "informed trust" [8], where users have a choice to comply with a given policy or temporarily override access rights. As an example of authority, access rights should be shared with all employees. Because of elimination of hierarchy structure, sharing authority is similar with the empowerment that may influence and enhance flexibility in system workflow.

Thus, we propose a new concept of ISSP through the case of ERM system. As an example of information security system, the ERM system is a set of tools and methods for controlling access to information assets. ERM systems define document access rules to protect organizational information assets. The major functionalities of ERM systems include logging content usage, watermarking, assigning rights per document per user, and limiting document usage. The ERM rules are an instantiation of ISSP addressing organizational policies. Conventional ERM (CONT-ERM) system is operated by typical control-based as a hierarchical mechanism.

On the other hand, our proposed new concept of ERM system is an empowerment-based ERM system (EMP-ERM). The system draws upon empowered system workflow that allows employees to override permissions temporarily. That is, similar to autonomy, EMP-ERM plays a role in increasing flexibility of workflow by allowing discretion or choice [9].

Thus, the aims of this study are the following. First, we explain our new approach of increasing compliance

${ }^{1}$ http://www.isdecisions.com/insider-threat-persona-study/ (retrieved 4-Apr-2017)

\section{$\mathrm{H}$ I C S S}

ISBN: 978-0-9981331-1-9

(CC BY-NC-ND 4.0) 
motivation using empowered system workflow. Second, we propose a research model through the lens of a deterrent control (auditing), psychological ownership, rational choice, and its antecedents. Psychological ownership is influenced by the organizational trust that affects employee's in-role behavior (i.e., ISSP compliance). However, information security environment does not promote psychological ownership since organizations compel employees to comply with ISSP without informed trust. As for deterrent countermeasures, organizations implement audits to ensure information security. Although the implementation of audit is meant to deter employee's inappropriate behavior, employees are not likely to conform to monitoring [10]. Individuals tend to bypass/circumvent systems when they perceive the system workflow as not beneficial [3]. Thus, we should consider psychological ownership, awareness of auditing, and perceived benefit to increase compliance motivation.

Finally, we conduct a comparative analysis of CONT-ERM system versus EMP-ERM system to verify the effectiveness of EMP-ERM system based on the above three perspectives.

\section{Research background}

\subsection{Enterprise digital rights management system}

For this study, we use the term "ERM rules" as one example of ISSP. ${ }^{2}$ ERM systems are often known as Information Rights Management or Digital Rights Management systems. Beyond protecting data assets outside of the organization, ERM systems enable data assets protection from unauthorized users within the trusted environment of the organization [11]. Since the protected data is only accessible via a predefined set of authorizations, the ERM system is an effective way to protect confidential information and to prevent organizational data leaks [11].

CONT-ERM system has been introduced to permit organizations to control information assets better. However, the CONT-ERM system follows a "closed model" form where anything that is explicitly unauthorized is prohibited [12]. Due to the closed model form, employees may violate the organizational security policies of the work system [2].

On the other hand, EMP-ERM is based on the notion of the exception management model to overcome the deficiencies (e.g., the likelihood of circumvention of ISSP, sharing password and ID) of

\footnotetext{
${ }^{2}$ In this paper, we use the term ERM rules interchangeably with the term ISSPs since ERM rules represent instantiations of ISSPs.
}

CONT-ERM systems. Exception management refers to active ERM rules management, where exceptional case is managed in the form of traceable and auditable claims [12]. The EMP-ERM refers to employees' autonomy to access information assets on a "per-needbasis” without formally asking for the administrator's permission. While the CONT-ERM system assumes distrust and thus limits all employees, informed trust assumes that most employees will follow organizational policies.

EMP-ERM system provides the user with flexibility by allowing a one-off permission (Figure C1, Appendix C) to override the access rights with access logs (Figure C2, Appendix C). Overall, the main difference between CONT-ERM and EMP-ERM is whether employees' performing security-related tasks are controlled by a trusted employee or by an administrative process.

\subsection{Psychological ownership}

People tend to equate feelings of possession with a feeling of ownership [13]. Psychological ownership (PO) is defined as a state of mind in which an individuals' perception of the object (material or immaterial) as "mine" [14]. PO is based on being psychologically tied to an object that can develop towards various tangible (i.e., technology) and intangible (i.e., knowledge) objects [14]. The theory of PO proposes three main routes that lead to the state of PO [14].

First, PO increases when individuals perceive control over objects. Perceived control refers to the ability to use and to control the use of objects [15]. The experienced control of a target can be the extended self and is regarded as a part of the self [14, 16, 17]. For example, employees can have a feeling of PO when they experience control over an assigned task without administrative control. Second, self-investment occurs when individuals devote time, effort, and energy to perform a task or create a product. Third, intimate knowledge of the target was shown to increase PO. An intimate association with the task (or system) increases individuals' familiarity with that task. For example, PO is experienced when individuals are given access to organizational information. Thereby, individuals' feelings of ownership toward obtained organizational information are likely to increase.

ERM rules compliance behavior can be considered as prevention focused PO [17]. Prevention-focused PO is more concerned with the avoidance of punishment and seeks to ensure safety.

Research on organization behavior suggests that PO is associated with certain desirable employee behaviors as well as positive outcome such as role behavior and 
extra-role behavior, citizenship behavior, commitment, satisfaction, and encouraging productivity [14].

In IS research, existing studies have shown a relationship between $\mathrm{PO}$ and behavioral intention. With respect to system usage, $\mathrm{PO}$ is affected by user participation, and significantly affects clinical information system usage intention [18]. Additionally, PO influences intention to perform a security-related behavior to protect one's computer [19]. In the context of the online game, perceived control increases players' PO toward the game, which is positively associated with E-Loyalty toward online games [20].

Thus, psychological ownership could be a notable motive for behavioral compliance intention in information security.

\subsection{Awareness of audit}

The audit is not the same as monitoring. Monitoring is a continuous process of tracking and recording employee's network activities, while auditing is the evaluation of a person's activity based on monitoring output [21]. The audit carries out monitoring output to evaluate the accuracy of financial records and the reliability of the systems, which includes the storage, transport, and processing of transactions (i.e., logs) [22]. Audit plays a role in increasing individual's rule compliance. For example, audit rates affect tax compliance [24, 25]. The awareness of monitoring has been widely discussed in information systems research [e.g., 26]. However, to date, the relationships between awareness of audits and compliance behavior has been scant. Monitoring is likely to cause deviant behavior such as computer misuse because people engage in reactance behavior [26].

Alm et al. [27] showed that audit rates increase tax compliance, which is consistent with the notion that audit rates increase compliance with rules because of the probability of detection. In addition, auditing has a role of evaluation that makes individuals create more informed decisions to either disapprove or approve actions [28]. Aware of auditing plays a role in increasing individuals’ appropriate behavior.

\subsection{Perceived benefit}

Perceived benefit (PB) is in part related to the health belief model, which attempts to explain and predict people's health behavior. Originally, the health belief model had been used to explain preventive health behaviors. Health behaviors are deemed as "any activity undertaken by a person who believes himself to be healthy to prevent disease or to detect disease at an asymptomatic stage.” [30: p.2]
According to the Health belief model, a person performs a recommended health action depending on his or her perceptions of the health action's perceived benefits in preventing or reducing susceptibility or severity or both [30]. Furthermore, when a behavior's potential benefit exceeds the cost, individuals will assume the behavior. Therefore, perceived benefit is associated with rational behavior/choice theory. This theory suggests that rational actors make their decisions or choices within a benefit-cost framework [31]. PB refers to one's beliefs in the efficacy of the advised action to reduce risk or seriousness of impact and to encourage the positive likelihood of compliance [33, 34]. Prior research has shown that PB has a positive influence on behavioral intentions such as adoption of Electronic Data Interchanging (EDI) [3436], corporate websites [35] and Internet banking [37], and Enterprise Resource Planning (ERP) System usage [38]. Within the IS security domain, Ng, Kankanhalli [39] found that PB was a significant determinant of security behavior since users were aware of the effectiveness of security controls about making decisions to perform the appropriate preventive behavior.

\section{Hypotheses and Research Model}

\subsection{Psychological ownership and intention to Comply with ERM rules}

We propose that psychological ownership (PO), defined as the extent in which an individual feels that the ERM system is "mine" [14], as a determinant of the intention to comply with ERM rules. ERM rules compliance as in-role behavior [40] is affected by PO because it is correlated with perceived responsibility [41]. Responsibility plays a pivotal role in increasing security-related behavior [42]. We define intention to comply with ERM rules as individual's intention to follow the policies and requirements as predefined in the ERM rules. The theory also proposes that PO plays a role in shaping counterproductive organizational behavior (e.g., breach of confidential data) [43].

Employee's autonomy in the work environment affects the creation of PO [44]. Individuals tend to accept full responsibility for their activities when they feel high levels of autonomy [45]. CONT-ERM users tend to have a lack of autonomy when they are performing security-related tasks through ERM system. The lack of autonomy in the working procedure may be likely to engage deviant behavior as a bypass/circumvent organizational policy [4]. In contrast, EMP-ERM users are relatively more autonomous in performing security-related tasks and 
may be likely to be less involved in deviant behavior than CONT-ERM users. Thus, we hypothesize:

Hypothesis 1: The effect of psychological ownership of EMP-ERM users on intention to comply with ERM rules is stronger than that of CONT-ERM users.

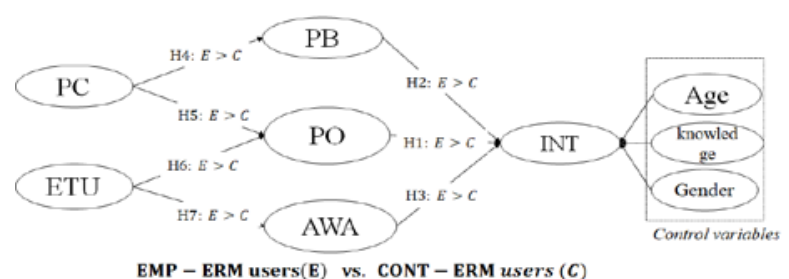

Figure 2. Research model

\subsection{Perceived benefit and intention to comply with ERM rules}

We define $\mathrm{PB}$ as individual's belief regarding the effectiveness of complying with ERM rules. According to rational choice theory, individuals make their decision or choices within the benefit-cost framework. In the security environment, complying with ISSP is regarded as cost [41]. In the context of ERM, unauthorized employees facing an exceptional case have to wait until they get permission from an administrator. Without permission, the employees have to wait until they can access the CONT-ERM system, which results in wasted time. Thus, employees are likely to choose to reduce their cost by circumventing/bypassing the ERM rules. Whereas, the EMP-ERM system does not impede user's system use since the system allows exceptional cases. EMP-ERM system user has perceived benefit of following ERM rules that are likely to increase compliance intention. Thus, we hypothesize:

Hypothesis 2: The effect of perceived benefit of EMPERM users on intention to comply with ERM rules is stronger than that of CONT-ERM users.

\subsection{Awareness of audit and intention to comply with ERM rules}

We define awareness of adudit (AWA) as the extent in which an the extent to which individuals are monitored and evaluated during use of the ERM system. Employees have a higher probability of compliance if they are aware of being audited [46]. Extending these findings to those in this study about the awareness of ERM audits can drive intention to comply with ERM rules.

EMP-ERM users are entrusted with the ability to override ERM rules. While such informed trust enables employees to complete their task efficiently, it also increases their level of awareness. This is because, under CONT-ERM, it is the administrator that overrides the system (i.e., the audit implicit). However, for the EMP-ERM, the auditing system requires the user to document the reason for the override (i.e., the audit is explicit). Therefore, EMP-ERM user is stronger awareness of the audit than CONT-ERM. Taken together, we hypothesize that

Hypothesis 3: The effect of awareness of an audit of EMP-ERM users on intention to comply with ERM rules is stronger than that of CONT-ERM users.

\subsection{Perceived control}

We define perceived control(PC) as the extent of the individuals' ability to control the ERM system. Perception of control of a target may increase the feelings of ownership [44]. EMP-ERM users have more control over the system workflow than CONTERM.

The EMP-ERM system can be considered as nonroutinized technology since EMP-ERM allows exceptional cases that offer the flexibility of the system. The flexibility in the system increases the EMP-ERM users' degree of control over the system [47]. Furthermore, the flexibility and informed trust afforded by the EMP-ERM system increases users' perceived benefits. As discussed above, perceived control increases perception of PO. Thus, we hypothesize:

Hypothesis 4: The effect of perceived control of EMP-ERM users on perceived benefit is stronger than that of CONT-ERM users.

Hypothesis 5: The effect of perceived control of EMP-ERM users on psychological ownership is stronger than that of CONT-ERM users.

\subsection{Effort to use}

The effort to use (ETU) refers to the employee' experience that effort to use the ERM system. Employees' effort is an antecedent of PO [14]. In this study, we measure effort to use as the frequency of requesting system permission. Employees are needed effort when they complete security-related task (i.e., accessing ERM) such as requesting permission to print documents.

Both EMP-ERM and CONT-ERM, users have the same task to complete. However, the user experience of each group is different since CONT-ERM users face more restrictions while EMP-ERM is given the discretion to override permissions when necessary. As mentioned above, positive user experience promotes 
PO [48]. Thus, CONT-ERM users are less likely to have a feeling of PO compare with EMP-ERM users.

Hypothesis 6: The effect of the effort to use of EMP-ERM users on psychological ownership is stronger than that of CONT-ERM users.

As mentioned above, the audit trail for the CONTERM users is implicit. Therefore, the frequency of permission requests is unlikely to have much effect on their audit awareness. However, for the EMPERM users, the audit system is explicit and has to be addressed every time a request is executed as shown in Figure C2. Appendix C. Thus, we hypothesize:

Hypothesis 7: the effort of use the ERM system effect on awareness of audit is higher for EMP-ERM users than for CONT-ERM users.

\section{Research methodology}

\subsection{Research design}

To compare users' attitude towards CONT-ERM and EMP-ERM, we use Fasoo.com's ERM system. Fasoo.com ${ }^{3}$ is a South Korean software company that was founded in 2000. The company has maintained leadership in the ERM market by deploying solutions for more than 2,000 projects globally. Fasoo.com 's ERM allows organizations to prevent unintended information disclosure and ensures a secured persistent collaboration across organizational boundaries. As an example of an EMP-ERM system, we use the provisional license function, developed by Fasoo.com in 2012. We collected data for this study via a field survey for one month. The survey questionnaire was distributed on paper to 28 companies and 125 for EMPERM users and 211 for CONT-ERM users. We collected data for this study via a questionnaire.

\subsection{Scale development}

To develop our survey instrument, we borrowed measures mainly from previous research, and we attempted to develop a new instrument. Regardless of the control variables, all of the constructs in the model were measured with multiple items, and each item was measured by using a 7-point Likert scale as $1=$ strongly disagree to $7=$ strongly agree. We adapted the measure for this study, which is intention to comply with ISSP from [49]. To assess awareness of audit and perceived benefit, we developed our scales based on the definition of the construct as mentioned earlier. The perceived control measure consisted of four items and was adapted and added from [50]. Finally, to measure

\footnotetext{
${ }^{3}$ http://en.fasoo.com/?lang=en
}

psychological ownership, we used three items adapted from [44]. The questionnaire is shown in Appendix A.

\section{Data analysis and results}

We used structural equation modeling (SEM) with the partial least square (PLS) estimation technique to test our research model. The SEM approach enables to test the causal relationship, and PLS is well suited for exploratory research and to test complex models that include moderating effects [61]. Furthermore, covariance-based SEM requires a normal distribution of the data, whereas PLS does not [53]. For this study, we initially tested our research model using linear PLS software (i.e., SmartPLS 2.0). However, some of the hypotheses were unsupported (Appendix B). Furthermore, the bivariate data plot of the relationship depicts the nonlinear relationship. For example, the plot of the relationship between awareness of audit and intention to comply with ERM rules supports nonlinear ("U” curve shape) relationship (Figure B1, Appendix B). Nonlinear relationship or asymmetry effect has been conducted in IS literature [e.g., 51].

Hence, we consider the possible nonlinear relationships that may exist in the proposed model. We utilized WarpPLS software to test a nonlinear assumption model [52]. WarpPLS can handle both linear and nonlinear ("warp" shape as "S" or "U" shape) relationships between variables, which often are encountered in cognitive and behavioral research [51].

\subsection{Instrument validation}

To ensure convergent validity and reliability, the individual item should be met by three criteria $[54,55]$. First, all item loading values should be greater than 0.6. Second, composite reliability should be greater than 0.8 . Finally, average variance extracted (AVE) should be greater than 0.5 or the square root of AVE should be greater than 0.7 .

Based on the criteria, the PLS results achieved a satisfactory level of convergent validity. As shown in Table 1, all of the measurement item loadings were above the recommended value of 0.7 (all significant, $p<0.001$ ). Furthermore, composite reliabilities of all constructs were above 0.8 , and the square root of AVE was greater than 0.7 for each construct.

To satisfy discriminant validity, the AVE of a construct should be greater than its correlations with all other constructs [54]. Table 2. depicts that the square root of the AVE for each construct was greater than the correlation between the AVE and all the other constructs. Thus, this study satisfied the criterion for discriminant validity. 


\subsection{Structural model}

We tested hypotheses using the structural model of PLS. To satisfy predictive and explanatory quality, the P-values of Average path coefficient (APC), average R-square (ARS) and average adjusted R-squared (AARS) should be below p-value 0.05 [55], and the value of average block VIF (AVIF) and average full collinearity VIF (AFVIF) should be below 3.3 [56]. Tenenhaus GoF (GoF) refers to that measure of a model's explanatory power [57]. The GoF is: small-if equal to or great than 0.1 , medium-if equal to or greater than 0.25 , large-if equal to or greater than 0.36 [58]. The values of all measure are satisfied criteria and not critical problems in this model. Thus, as shown in Table 3, our proposed model has predictive and explanatory power.

Table 1. Item loadings and cross-loadings

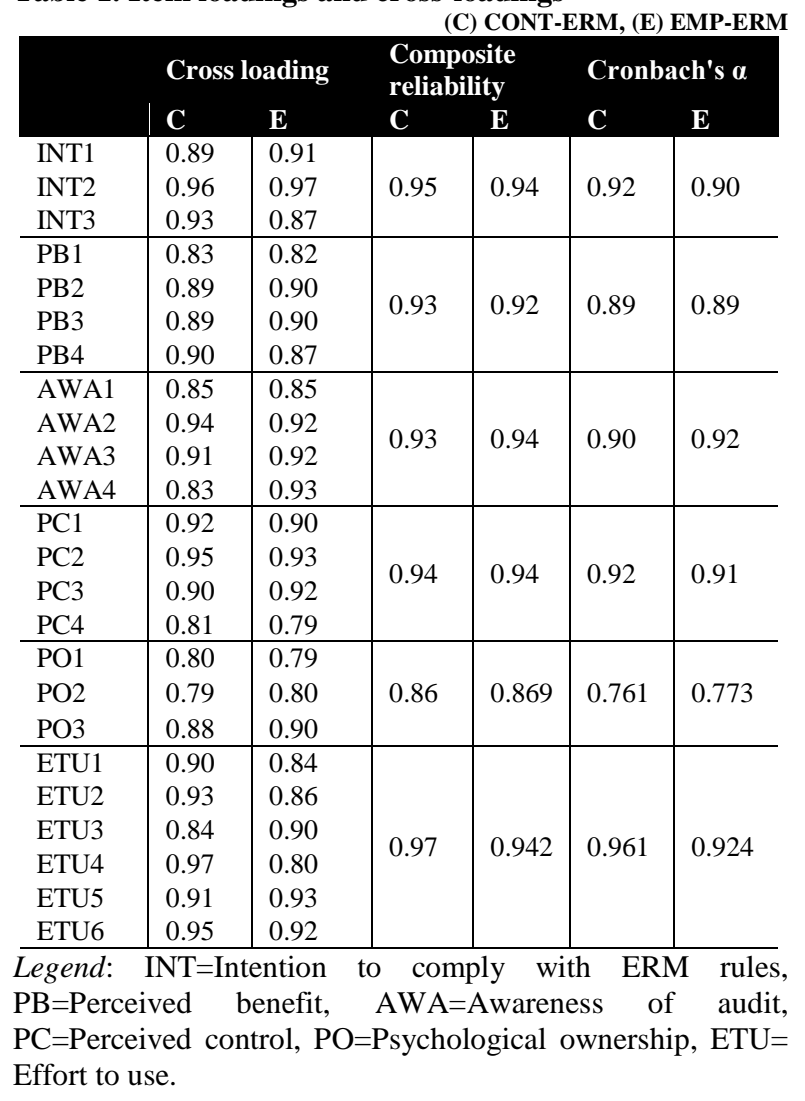

Table 2. AVE and latent variable correlations

\begin{tabular}{lllllll|}
\multicolumn{7}{c}{ A. CONT-ERM system } \\
INT & PB & PO & PC & ETU & AWA \\
INT & $\mathbf{0 . 9 3}$ & & & & & \\
PB & 0.346 & $\mathbf{0 . 8 7 7}$ & & & & \\
PO & 0.219 & 0.354 & $\mathbf{0 . 8 2 3}$ & & & \\
PC & 0.129 & 0.337 & 0.318 & $\mathbf{0 . 8 9 5}$ & & \\
ETU & -0.161 & -0.141 & -0.137 & 0.061 & $\mathbf{0 . 9 1 6}$ &
\end{tabular}

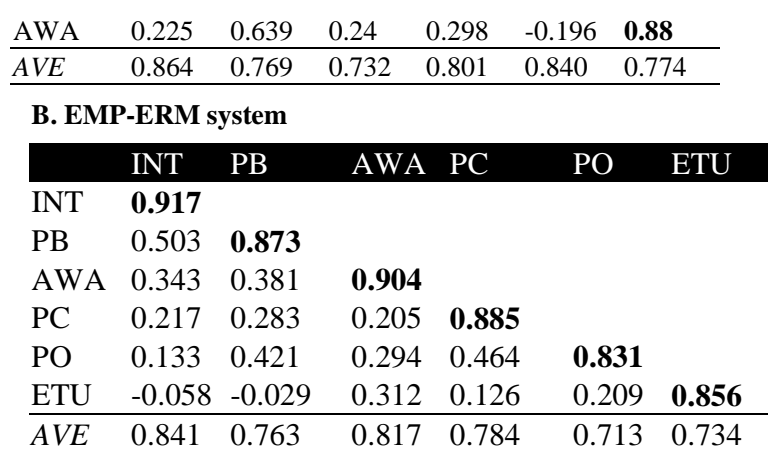

Notes: Average variances extracted (AVE),

Square roots of average variances extracted (AVEs) shown on diagonal.

Table 3. WarpPLS model fit and quality indices

\begin{tabular}{|c|c|c|}
\hline Measure & Value & Criteria \\
\hline APC & C: $0.195(p<0.001)$ & \multirow{6}{*}{ Acceptable if $p<0.05$} \\
\hline & E: $0.283(p<0.001)$ & \\
\hline \multirow[t]{2}{*}{ ARS } & C: $0.153(p<0.005)$ & \\
\hline & E: $0.304(p<0.001)$ & \\
\hline \multirow[t]{2}{*}{ AARS } & C: $0.143(p<0.01)$ & \\
\hline & E: $0.292(p<0.001)$ & \\
\hline \multirow[t]{2}{*}{ AVIF } & C: 1.312 & \multirow[t]{2}{*}{ Acceptable if $<=3.3$} \\
\hline & E: 1.209 & \\
\hline \multirow[t]{2}{*}{ AFVIF } & C: 1.564 & \multirow[t]{2}{*}{ Acceptable if $<=3.3$} \\
\hline & E: 1.688 & \\
\hline \multirow[t]{2}{*}{ GoF } & C: 0.362 & Small: \\
\hline & E: 0.508 & $\begin{array}{l}\text { Medium: } \\
\text { Large: } 0.36 \leq\end{array}$ \\
\hline
\end{tabular}

The results of PLS analyses of both group models are shown in Fig 2. To compare the research model across two ERM systems, a multi-group PLS analysis was conducted by comparing differences in path coefficients of corresponding structural path coefficient for between CONT-ERM and EMP-ERM users [59] (see Table 4). The analysis revealed that the path coefficient from psychological ownership to intention comply with ERM rules are shown EMPERM user is higher than of the CONT-ERM user.

However, the difference was not statistically significant, and therefore $\mathrm{H} 1$ was not supported. Similarly, the path coefficient from perceived benefit to compliance intention is shown EMP-ERM user is higher for EMP-ERM user than CONT-ERM user, but the difference was not supported statistically. Thus, H2 was not supported. Consistent with H3, there were significant differences between awareness of audit on intention to comply with ERM rules across twosystem user (H3 supported). Concerning perceived control, there were no significant differences between the influence of perceived control on perceived benefit and psychological ownership. Thus, $\mathrm{H} 4$ and $\mathrm{H} 5$ were not supported. Regarding effort to use, the path coefficient from effort to use to psychological ownership and awareness of audit for EMP-ERM user 
were significantly higher than the corresponding path coefficient for the CONT-ERM user, thus supporting H6 and $\mathrm{H} 7$.

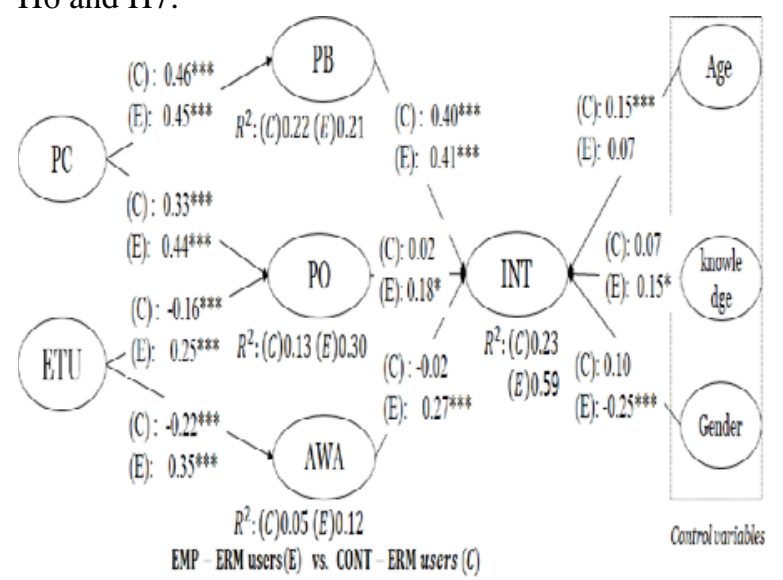

Figure 2. PLS model

Table 4. Path comparison statistics

\begin{tabular}{|l|l|l|}
\hline Path & $\begin{array}{c}\text { t- } \\
\text { value }\end{array}$ & $\begin{array}{l}\text { Significant } \\
\text { difference }\end{array}$ \\
\hline H1: PO $\rightarrow$ INT & 1.54 & $\mathrm{n} / \mathrm{s}$ \\
\hline H2: PB $\rightarrow$ INT & 0.14 & $\mathrm{n} / \mathrm{s}$ \\
\hline H3: AWA $\rightarrow$ INT & 2.77 & Yes $(\mathrm{p}<0.01)$ \\
\hline H4: PC $\rightarrow$ PB & 0.15 & $\mathrm{n} / \mathrm{s}$ \\
\hline H5: PC $\rightarrow$ PO & 1.05 & $\mathrm{n} / \mathrm{s}$ \\
\hline H6: ETU $\rightarrow$ PO & 3.91 & Yes $(\mathrm{p}<0.001)$ \\
\hline H7: ETU $\rightarrow$ AWA & 5.25 & Yes $(\mathrm{p}<0.001)$ \\
\hline
\end{tabular}

\section{Results and discussion}

The purpose of this study was to delineate the new concept of ERM system (i.e., EMP-ERM) and compare two different systems (CONT-ERM versus EMP-ERM) through three perspectives and their antecedents.

In the CONT-ERM system (Figure 2), perceived benefit was only effective at intention to comply with ERM rules. Psychological ownership did not have a significant effect on intention to comply with ERM rules. This result extends prior work conducted on home setting that found psychological ownership to be a predictor of security behavior. However, in the workplace setting, especially security system, psychological ownership does not have a significant relationship with compliance behavior. Perceived control has a positive effect on perceived benefit and psychological ownership for CONT-ERM users. On the other hand, effort to use was shown negative effect on psychological ownership and awareness of audit. This result may imply employees' constrained working experience increase negative emotion toward ERM system. Therefore, implicit in system (i.e.,
CONT-ERM) may lead to ignorance of awareness of deterrence.

In contrast, for the EMP-ERM system (Figure 2), perceived benefit, psychological ownership, and awareness of audit increase intention to comply with ERM rules. Concerning awareness of audit, allowing exceptional cases provides that the assessing ERM system is recorded as logs explicitly. Thereby, employees are aware of audit that increases compliance intention. As expected, psychological ownership increase compliance intention. This result is consistent with previous study [19]. Perceived benefit is also consistent in previous study that individuals engage in following ISSP when they perceived benefit toward behavior [49].

Regarding perceived control, perceived benefit and psychological ownership were influenced by employee's perceived control over the ERM system. Contradictory to CONT-ERM, effort to use increases psychological ownership and awareness of audit. These finding support our theoretical arguments that EMP-ERM users' positive experience and explicit audit system increase psychological ownership and awareness of audit respectively.

Path comparison between CONT-ERM and EMPERM showed that awareness of audit appears to comply with ERM rules for EMP-ERM users. Contrary to expectations, perceived benefit and psychological ownership did not have a stronger effect on intention to comply with ERM rules for EMP-ERM. While different factors appear to shape perceived benefit for CONT and EMP-ERM users, perceived benefit to comply with ERM rules results in compliance intention across two system users. This is noteworthy because it implies that violation of ISSP does not stem from the lack of autonomy in performing security-related task.

Perceived control did not have a stronger effect on psychological ownership for EMP-ERM users than CONT-ERM users.

As predicted, effort to use had a stronger association with psychological ownership and awareness of audit. Thus, our results suggest that explicit audit system increase higher the perception of deterrence than implicit audit system.

\section{Implications}

Enterprises rely on control-based security method as governed by organization. Although control-based approach is effective method to prevent security incident, circumventing organizational rules may occur because of inflexibility in system workflow. In this regard, this study shows that how employees are given autonomy 
(i.e., self-government) can affect behavioral compliance intention. Thereby, this study offers several implications.

For the research implication, this study attempted to approach both descriptive knowledge and prescriptive knowledge [60] to be real problem-solving. In the information security literature, a number of studies identified compliance motivation under control-based system workflow. Thus, this research sheds light on empowerment-based motivation, which can help to comply with information security policies. By comparing the underlying process by psychological ownership, which shows ERM rules compliance intention across two ERM system, this study emphasizes the difference between control-based versus empowerment-based compliance intention. Prior information security research incorporated the theory of PO [19]. We extend PO by incorporating the antecedents of PO, and we explain the differences between conventional and empowerment-based ERM.

For the implication for practice, the enterprise digital rights management system has become an important technical means of organizational information assets. At present, the ERM market is expected to reach USD 2.9 million by the year 2020. ${ }^{4}$ However, the conventional way of preventing information assets may reduce compliance intention because of the system workflow inflexibility. Employees' attempting to circumvent the policies can be an untraceable way to detect. Thereby, circumventing the policies could be an organizational drawback such as confidential information breaches. Thus, our proposed empowerment-based ERM system as given control over the system overcome the deficiency of bypass organizational rules in an auditable and informed way. As a result, employees have a feeling of psychological ownership of ERM system, awareness of audit and perceived benefit to comply with ERM rules, which leads to increase compliance intention.

\section{References}

[1] Wall, J.D., P. Palvia, and P.B. Lowry, “Control-Related Motivations And Information Security Policy Compliance: The Role Of Autonomy And Efficacy", Journal of Information Privacy and Security, 2013. 9(4), pp. 52-79.

[2] West, R., "The psychology of security" Communications of the ACM, 2008. 51(4), pp. 34-40.

[3] Alter, S., "Theory of Workarounds”, Communications of the Association for Information Systems, 2014. (34), pp. 10411066.

[4] Ferneley, E.H. and P. Sobreperez, "Resist, comply or workaround? An examination of different facets of user engagement with information systems”, European Journal

\footnotetext{
4 http://www.marketsandmarkets.com/PressReleases/digital-rightsmanagement.asp (retrieved 17-MAY-2017)
}

of Information Systems, 2006. 15(4), pp. 345-356.

[5] puhakainen, P. and R. Ahonen, Design theory for information security awareness. Unversity of Oulu Press, Oulu, Finland, 2006.

[6] Morin, J.H. and M. Pawlak. A Model for Credential Based Exception Management in Digital Rights Management Systems. in Internet Monitoring and Protection, 2007. ICIMP 2007. Second International Conference on. 2007. IEEE.

[7] Boudreau, M.-C. and D. Robey, "Enacting integrated information technology: A human agency perspective”, Organization science, 2005. 16(1), pp. 3-18.

[8] Morin, J. and M. Pawlak, "From Digital Rights Management to Enterprise Rights and Policy Management: Challenges and Opportunities. Advances in Enterprise Information Technology Security", Information Science Reference, IGI Global, Hershey, PA, 2007: pp. 169-188.

[9] Breaugh, J.A., "The work autonomy scales: Additional validity evidence" Human Relations, 1989. 42(11): pp. 1033-1056.

[10] Posey, C., Bennet, B, Roberts, T and Lowey, PB, "When computer monitoring backfires: Invasion of privacy and organizational injustice as precursors to computer abuse", Jounral of Information System Security, 2011. 7(1): pp. 2447

[11] Chang, C.-C., J.-H. Yang, and D.-W. Wang, “An efficient and reliable E-DRM scheme for mobile environments. Expert Systems with Applications” 2010. 37(9): pp. 61766181.

[12] Morin, J.-H., "Exception based enterprise rights management: Towards a paradigm shift in information security and policy management”, International Journal On Advances in Systems and Measurements 2008 (1): pp.1-15

[13] Furby, L., "Possession in humans: An exploratory study of its meaning and motivation", Social Behavior and Personality: an international journal, 1978. 6(1): pp. 49-65.

[14] Pierce, J.L., T. Kostova, and K.T. Dirks, "Toward a Theory of Psychological Ownership in Organizations", The Academy of Management Review, 2001. 26(2): pp. 298-310.

[15] Rudmin, F.W. and J.W. Berry, "Semantics of ownership: A free-recall study of property”, The Psychological Record, 1987. 37(2): pp. 257-268.

[16] Belk, R.W., "Possessions and the extended self", Journal of Consumer research, 1988: pp. 139-168.

[17] Avey, J.B., et al., "Psychological ownership: Theoretical extensions, measurement and relation to work outcomes", Journal of Organizational Behavior, 2009. 30(2): pp. 173191.

[18] Barki, H., G. Paré, and C. Sicotte, "Linking IT implementation and acceptance via the construct of psychological ownership of information technology", Journal of Information Technology, 2008. 23(4): pp. 269280.

[19] Anderson, C.L. and R. Agarwal, "Practicing safe computing: a multimedia empirical examination of home computer user security behavioral intentions”, MIS Quarterly, 2010. 34(3): pp. 613-643.

[20] Moon, J., Hossain, M., Sander, G., Garrity, E., Jo, S., "Player commitment to massively multiplayer online roleplaying games (MMORPGs): An integrated model”, International Journal of Electronic Commerce, 2013. 17(4): 
pp. 7-38.

[21] Urbaczewski, A. and L.M. Jessup, "Does electronic monitoring of employee internet usage work?”, Communications of the ACM, 2002. 45(1): pp. 80-83.

[22] Flowerday, S., A. Blundell, and R. Von Solms, "Continuous auditing technologies and models: a discussion”, Computers \& security, 2006. 25(5): pp. 325331.

[23] Dubin, J.A., M.J. Graetz, and L.L. Wilde, "The effect of audit rates on the federal individual income tax, 1977-1986", National Tax Journal, 1990. 43(4): pp. 395-409.

[24] Witte, A.D. and D.F. Woodbury, “The effect of tax laws and tax administration on tax compliance: The case of the US individual income tax”, National Tax Journal, 1985: pp. 1-13.

[25] Chang, S.E., A.Y.C. Liu, and S.M. Lin, "Exploring privacy and trust for employee monitoring. Industrial Management \& Data Systems”, 2015. 115(1): pp. 88-106.

[26] Brehm, J.W., "Psychological reactance-theory and applications”, Advances in consumer research, 1989. 16: pp. 72-75.

[27] Alm, J., B.R. Jackson, and M. McKee, "Estimating the determinants of taxpayer compliance with experimental data”, National Tax Journal, 1992. 45(1): pp. 107-114.

[28] Geen, R.G., "Social motivation", Annual review of psychology, 1991. 42(1): pp. 377-399.

[29] Kasl, S.V. and S. Cobb, "Health behavior, illness behavior and sick role behavior: I. Health and illness behavior", Archives of Environmental Health: An International Journal, 1966. 12(2): pp. 246-266.

[30] Rosenstock, I.M., "Why people use health services", The Milbank Memorial Fund Quarterly, 1966. 44(3): pp. 94127.

[31] Michaels, J.W. and T.D. Miethe, "Applying theories of deviance to academic cheating”, Social Science Quarterly, 1989. 70(4): pp. 870-885.

[32] Rosenstock, I.M., "The health belief model and preventive health behavior", Health Education \& Behavior, 1974. 2(4): pp. 354-386.

[33] Becker, M.H., Radius, S.M., Rosenstock, I.M., Dranchman, R.H., Schuberth, K.C., Teets, K.C., "Compliance with a medical regimen for asthma: a test of the health belief model”, Public health reports, 1978. 93(3): pp. 268-277.

[34] Banerjee, S. and D.Y. Golhar, "Electronic data interchange: characteristics of users and nonusers", Information \& Management, 1994. 26(2): pp. 65-74.

[35] Beatty, R.C., J. Shim, and M.C. Jones, "Factors influencing corporate web site adoption: a time-based assessment”, Information \& management, 2001. 38(6): pp. 337-354.

[36] Jiménez-Martínez, J. and Y. Polo-Redondo, "The influence of EDI adoption over its perceived benefits", Technovation, 2004. 24(1): pp. 73-79.

[37] Lee, M.-C., "Factors influencing the adoption of internet banking: An integration of TAM and TPB with perceived risk and perceived benefit”, Electronic Commerce Research and Applications, 2009. 8(3): pp. 130-141.

[38] Wu, W.-W., "Segmenting and mining the ERP users' perceived benefits using the rough set approach", Expert Systems with Applications, 2011. 38(6): pp. 6940-6948.
[39] Ng, B.-Y., A. Kankanhalli, and Y.C. Xu, “Studying users' computer security behavior: A health belief perspective", Decision Support Systems, 2009. 46(4): pp. 815-825.

[40] Hsu, J.S.-C., et al., "The Role of Extra-Role Behaviors and Social Controls in Information Security Policy Effectiveness", Information Systems Research, 2015. 26(2): pp. 282-300.

[41] Van Dyne, L. and J.L. Pierce, "Psychological ownership and feelings of possession: Three field studies predicting employee attitudes and organizational citizenship behavior”, Journal of Organizational Behavior, 2004. 25(4): pp. 439-459.

[42] Shillair, R., Cotton, S.R., Tsai, H.S., Alhabash, S., LaRose, R., Rifon, NJ., "Online safety begins with you and me: Convincing Internet users to protect themselves", Computers in Human Behavior, 2015. 48: pp. 199-207.

[43] Mischel, W., "Toward a cognitive social learning reconceptualization of personality”, Psychological review, 1973. 80(4): pp. 252-283.

[44] Pierce, J.L., M.P. O'driscoll, and A.-M. Coghlan, "Work environment structure and psychological ownership: The mediating effects of control", The Journal of social psychology, 2004. 144(5): pp. 507-534.

[45] Deci, E.L., Eghrari, H., Ptrick, B.C., Leone, D.R., et al., "Facilitating internalization: The self-determination theory perspective”, Journal of personality, 1994. 62(1): pp. 119-142.

[46] Alm, J. and M. McKee, "Audit certainty, audit productivity, and taxpayer compliance”, National Tax Journal, 2006. 59(4): pp. 801-816.

[47] Brass, D.J., "Technology and the structuring of jobs: Employee satisfaction, performance, and influence", Organizational Behavior and Human Decision Processes, 1985. 35(2): p. 216-240.

[48] Paré, G., C. Sicotte, and H. Jacques, "The effects of creating psychological ownership on physicians' acceptance of clinical information systems”, Journal of the American Medical Informatics Association, 2006. 13(2): p. 197-205.

[49] Bulgurcu, B., H. Cavusoglu, and I. Benbasat, "Information security policy compliance: an empirical study of rationality-based beliefs and information security awareness”, MIS Quarterly, 2010. 34(3): pp. 523-548.

[50] Lee, Y. and A.N. Chen, Usability design and psychological ownership of a virtual world. Journal of Management Information Systems, 2011. 28(3): pp. 269308.

[51] Guo, K.H., Yuan, Y.F., Archer, N.P., Connelly, C.E., "Understanding Nonmalicious Security Violations in the Workplace: A Composite Behavior Model”, Journal of Management Information Systems, 2011. 28(2): pp. 203236.

[52] Kock, N., WarpPLS 5.0 User Manual. 2015. http://warppls.com/

[53] Chin, W.W., "The partial least squares approach to structural equation modeling”, Modern methods for business research, 1998. 295(2): pp. 295-336.

[54] Fornell, C. and D.F. Larcker, "Evaluating structural equation models with unobservable variables and measurement error”, Journal of Marketing Research, 1981. 18(1): pp. 39-5. 
[55] Rosenthal, R. and R.L. Rosnow, Essentials of behavioral research: Methods and data analysis. 1991: McGraw-Hill Humanities Social

[56] Kock, N. and G. Lynn, "Lateral collinearity and misleading results in variance-based SEM: An illustration and recommendations", Journal of the Association for Information Systems, 2012. 13(7): pp.546-580.

[57] Tenenhaus, M., Vinzi, V.E, Chatelin, Y.M., Lauro, C., "PLS path modeling", Computational statistics \& data analysis, 2005. 48(1): pp. 159-205.

[58] Wetzels, M., G. Odekerken-Schröder, and C. Van Oppen, "Using PLS path modeling for assessing hierarchical construct models: Guidelines and empirical illustration”, MIS Quarterly, 2009: pp. 177-195.

[59] Hovav, A. and J. D'Arcy, “Applying an extended model of deterrence across cultures: An investigation of information systems misuse in the US and South Korea”, Information \& Management, 2012. 49(2): pp. 99-110.

[60] Gregor, S. and A.R. Hevner, "Positioning and Presenting Design Science Research for Maximum Impact”, MIS Quarterly, 2013. 37(2): pp. 337-355.

[61] Pavlou, P. and Fygenson, M, "Understanding and predicting electronic commerce adoption: an extension of the theory of planned behavior”, MIS Quarterly, 2006. 30(1): pp. 115-143.

\section{Appendix A. Measurement instrument.} Intention to comply with the ERM policy

When I utilize ERM system,

1) I intend to comply with the ERM policy as requirements of the organization's information access rules and policies.

2) I intend to protect the organization's information and technology resources according to the requirements of the information access rules and policies.

3) I intend to carry out my responsibilities prescribed in the information access rules and policies.

Perceived Benefit

1) ERM system does not require time-consuming to comply with policies regarding e-mail communication with external organization or agencies.

2) ERM system improves my ability to comply with information access rules or policy.

3) ERM is more convenient for me to comply with information access rules or policy.

4) ERM is an effective way to comply with information access rules or policy.

Psychological Ownership of ERM

1) The ERM system is my system.

2) I feel a high level of ownership toward the ERM system.

3) I feel a high degree of responsibility for the ERM system.

Awareness of Audit

1) I am aware that ERM has functions to monitor the access and use of information resources.

2) I am aware that IT audits are conducted by systems that generate/collect/transmit information resources.

3) I am aware that IT audits are conducted when I share information with external organizations or agencies.

4) I am aware that Logs of employees' computing activities are created and analyzed for inappropriate access to information resources.

Perceived control

1) I feel that I have control over using ERM system.

2) I felt in control while using ERM system.

3) When using ERM system I feel in control.

4) Using ERM system is completely under my control.
Effort to use

How often do you request your permission to restricted document?

(1) Very rarely ------- (7) very often

1) Open 2) Edit 3) Screen capture 4) Decrypt 5) Print 6) Print watermark

\begin{tabular}{|c|c|c|}
\hline \multicolumn{3}{|c|}{$\begin{array}{l}\text { Appendix B. PLS result } \\
\text { nonlinear relationship. } \\
\text { 1) PLS result for CONT-ERM }\end{array}$} \\
\hline Path & Path & $R$-square \\
\hline $\mathrm{H} 1: \mathrm{PO} \rightarrow \mathrm{INT}$ & 0.08 & \multirow{3}{*}{0.16} \\
\hline $\mathrm{H} 2: \mathrm{PB} \rightarrow \mathrm{INT}$ & $0.32 * * *$ & \\
\hline H3: AWA $\rightarrow$ INT & -0.01 & \\
\hline $\mathrm{H} 4: \mathrm{PC} \rightarrow \mathrm{PB}$ & $0.34^{* * *}$ & 0.11 \\
\hline $\mathrm{H} 5: \mathrm{PC} \rightarrow \mathrm{PO}$ & $0.33^{* * *}$ & \multirow{2}{*}{0.13} \\
\hline H6: ETU $\rightarrow$ PO & $-0.16^{* * *}$ & \\
\hline H7: ETU $\rightarrow$ AWA & $-0.20 * * *$ & 0.04 \\
\hline
\end{tabular}

2) PLS result for EMP-ERM

\begin{tabular}{|c|c|c|}
\hline Path & Path & $R$-square \\
\hline $\mathrm{H} 1: \mathrm{PO} \rightarrow \mathrm{INT}$ & -0.08 & \multirow[t]{3}{*}{0.44} \\
\hline $\mathrm{H} 2: \mathrm{PB} \rightarrow \mathrm{INT}$ & $0.35 * * *$ & \\
\hline H3: AWA $\rightarrow$ INT & 0.11 & \\
\hline $\mathrm{H} 4: \mathrm{PC} \rightarrow \mathrm{PB}$ & $0.28^{* * * *}$ & 0.08 \\
\hline $\mathrm{H} 5: \mathrm{PC} \rightarrow \mathrm{PO}$ & $0.44 * * *$ & \multirow[t]{2}{*}{0.24} \\
\hline H6: ETU $\rightarrow$ PO & $0.15^{*}$ & \\
\hline H7: ETU $\rightarrow$ AWA & $0.31^{* * *}$ & 0.10 \\
\hline
\end{tabular}

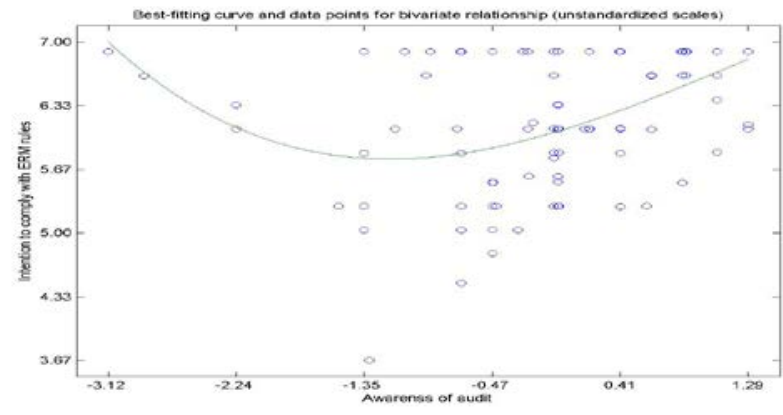

Figure B1. Example of Nonlinear Relationship (X-axis : AWA, Y-axis :INT)

Appendix C. Sample of functionality used in EMP-

\section{ERM}

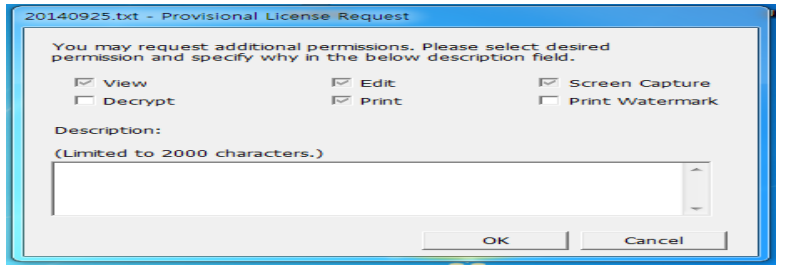

Figure C1. The function of exception management

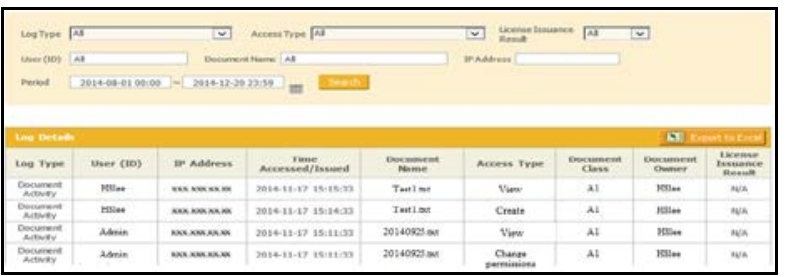

Figure C2. Audit report 